\title{
A Study on Knowledge Management on Working Productivity
}

\author{
${ }^{1}$ Karim Abboud \\ ${ }^{1}$ Management Studies, Lebanese American University, Beirut Campus, Beirut, Lebanon. \\ 1abboudlau110@hotmail.com
}

\author{
Article Info \\ Journal of Journal of Enterprise and Business Intelligence (http://anapub.co.ke/journals/jebi/jebi.html) \\ Doi: https://doi.org/10.53759/5181/JEBI202101013 \\ Received 15 January 2021; Revised form 12 March 2021; Accepted 02 April 2021. \\ Available online 05 July 2021. \\ (C)2021 Published by AnaPub Publications.
}

\begin{abstract}
Knowledge management nowadays had been considered as a main element for achieving organizational success and survival in today's knowledge age and competitive environments. The performance of the Lebanese Banking Sector nowadays is fluctuating, and the main reason behind that is the absence of knowledge management in the workplace and by that absence of communication among employees and managers in their workplace. The primary motivation which lies behind the research is to identify the importance of knowledge sharing, and how it affects employees' involvement and engagement in the workplace. The research had implemented both quantitative and qualitative methods, and the data were analyzed using both descriptive and inferential statistics to validate the research hypotheses scientifically. The findings of the research proved that there is a significant positive relationship between Knowledge enhancement, E-Learning, Knowledge management and organizational commitment.
\end{abstract}

Keywords - E-Learning, Knowledge Management, Knowledge Enhancement, and Organizational Commitment.

\section{INTRODUCTION}

The [1] claimed that many organizations are equipped with information management, which seeks to preserve, collect and disseminate knowledge throughout the enterprise in a world in which knowledge are increasingly regarded as the most critical resources of an organization. In [2] has been proposed to inspire and empower skilled individuals to use and share their understandings and develop new knowledge, in large part in knowledge management to build, provide, encourage and support reasonable learning conditions in associations. Knowledge is in the form of intelligence, awareness, contextualization and thought, according to Davenport and [3]. It is a powerful form of data available for use in choices and events. Organizations will accurately see which knowledge gives them a handle. [4] said the group would have a creative and concentrated advantage over knowledge or know-how. Knowledge has become a means of accomplishment. It is inherently unnecessary and impossible to be used as a weapon [5]. Despite its value and expertise, many organizations face difficulties in coping with the demands of the economy powered by learning. In many organizations, research institutions and various parts of the economy, the topic of information management is a moving subject today. Education has played a critical role in building and promoting monetary confidence among traditional assets of property, work and money. In the last decade, important work assessing information, like treatment, intellectual resources (human capital), society and the process over knowledge management have been recognized as critical factors, according to [6]. The evaluation aims to provide a theoretical model of casework to improve the research administration by compellingly reconciling these considerations and making active use of knowledge properties. It will emphasize the integrative effect on information management of processes, academic (human), society and methodology.

\section{An Overview of Knowledge Management}

The absence of the information management concept (KM), continues to decline in the business community and that can be observed from the last decade of the twentieth century. The business world has seen the emergence of innovation in the new information-age system. The caring for vital and strategic expertise in the new knowledge ecosystem and its ongoing growth allow companies to generate additional benefits. Knowledge management has now been extended to various segments, universities, administrative, agencies, research, and development etc. [7] also claimed that knowledge management is about how people trained can use and communicate their experiences to gain new experience and expertise. [8] explore whether and how knowledge management practices can be used in order to promote employee work satisfaction. Knowledge Management (KM) consists of a set of procedures for the development, dissemination and use of information in an entity [9]. As described in IFLA, KM is' a system in which authoritative knowledge is made (produced, captured) is placed out (protected, organized, coordinated) and used 
(imparted), used (implanted) and reused (changed) in order to enable an entity to achieve its objectives.' It involves formal information management and tacit knowledge sharing (i.e. skills/mastery / know-how) [10]. Of starters, within the group, minutes of meetings, resolutions, guidelines of notes, documentation, etc. and other records such as files, documents, government data, research papers are gathered inside organizations' associations and other material is retrieved. Tacit knowledge, though, integrated into the working people's brains through extensive knowledge of rules and regulations, job processes, etc. [11]. Tacit and specifically knowledge is considered to be the most important part of an organization's information, and the handling of which should be performed with the utmost care and should be the prime motive for all organizations [12].

According to [13], based on previous research, employees will be proactive, more creative, and innovative when they are satisfied with their work. They will do their job. Not many research studies on the management of information and job satisfaction to the organization were addressed, as mentioned by [14]. Therefore, while conducting Knowledge Management, the researcher intended to analyze job satisfaction in detail. [15] reveals that job efficiency can be improved if incremental fragments provide focal structures that enable the exposure of different divisions of an enterprise to new learning [15]. The relationship between KM and efficiency had been recognized with conspicuous inspection of facts, the management of knowledge, and its unique impact on employee performance [16]. Accordingly, Woods [17] mainly offers multinational organizations (MMC) and public offices and agencies for establishing and accepting information management in Malaysia. The insistence on improving information systems in their organizations has shown to be less on small-medium businesses (SMEs). KM activities continue to be discussed in Malaysia, where penetration is small. It involves companies with a large level of knowledge which are known to be highly structured entities [18].

\section{LITERATURE REVIEW}

\section{Concept of Knowledge Management}

The impact of knowledge management on employee satisfaction is the main aim of this research. Studies will recognize and examine in this respect, whether the application in knowledge management can have an impact on the job satisfaction of workers. Knowledge management is the willingness of an organization to acquire, archive, exchange and use knowledge with a common aim to improve their success and achievement. The successful use of information control unlocks members, according to [19]. Knowledge workers are adaptable and agile in order to manage their jobs according to their knowledge, expertise and activities. Based on its bookkeeping interest and its contribution to expertise, companies make progress in the business field and thrive in [20]. In [21] most specialists strongly recommend the collection and implementation of KM practices, such as the capturing and distribution of the best practices that effectively track consumer relations and provide active input. Malaysian companies have always been behind their distant partners from moving markets, given the uncertainty between the sectors. [22] has reported that 46\% (139 organizations) have formalized KM operations, with 303 educational and policy organizations overviewed. Irritably, only a small amount of 46 per cent (32 organizations) started use and evaluation (18 organizations). At the same time, larger groups were still in the underlying stages of study, review, planning, or setting up spending plans. It is not because companies did not know KM that the sluggish execution is based.

Instead, most Malaysian institutions as they did not know what the potential advantages of KM were, adopted a' sit back and watch' attitude to the introduction of KM projects within their organizations [23]. In comparison, an inability by institutions to understand $\mathrm{KM}$ is attributed to the crucial shortage of confirmatory studies on the interaction between KM's operation and work satisfaction. Many scholars with empirical support through the process review approach [24] have stressed how the findings could not be generalized by a broader population even though significant correlations between the KM procedures and KM implementation were established. From now on, the study must cover this void with the exact acceptance that most organizations, in particular information-based companies, must be confident of the relationship between these components. This would promote appropriate KM activities to gain an improved strategic advantage.

\section{KM Practices}

$\mathrm{KM}$ relates to the distinction and use of the aggregated data in an enterprise to support the company [25]. KM is reportedly a mechanism of information, such as the processing, collection, distribution, transition, and compliance, according to [26]. The independent method of information formation, storage and transmission by Nonaka and Takeuchi has been announced. Demarest and Pruzinsky have also suggested KM mechanisms such as information formation, codification, accumulation of knowledge, knowledge sharing, and preservation of knowledge.

\section{Knowledge Acquisition}

According to Zahra and George, the collection of details from extra-organized outlets remains a question of authoritative activity. For a wide range of organizations, global networks and collaboration partnerships become 
essential information outlets. If the organization works, its clients plan a particularly crucial meeting from which information should be obtained. For starters, the highly-developed information gathering processes are characteristic of customer feedback networks, data mining, business intelligence and collaboration with collaborators or research institutes. The acquisition of knowledge is a complex and continuous process. The ability to develop original thoughts, information, and structures and link them within the company requires knowledge development.

\section{Knowledge Sharing}

King has observed that information exchange or diffusion is one of the key components of knowledge management practices. This determines which phase members should send bosses and subordinates their thoughts and productive skills to accomplish their tasks and improve their performance. On the other side, it also speaks about the system used in the different section and entities of the company by workers for the collection or exchanging of data. The approaches used to gather, develop, give, and use information in a viable way for fulfilling different goals are provided by the management of knowledge by Awad. Essentially it is a multidisciplinary technique with defining techniques and processes. The idea that workplace information is communicated with others to maintain successful knowledge management practices is a significant factor to be considered. According to Trivellas, based on previous research, companies are unable to pursue effective information management practices without employee involvement, because employees do not share knowledge. Although several studies have found the role of organizational culture and the system of knowledge sharing, this research was also sponsored by King and needs to find out its effects on employee satisfaction.

\section{Knowledge Creation}

Knowledge management refers to the ability of the organization, from technical methods to product and managerial activity, to develop new and useful concepts and strategies about different parts of operational activities. According to Eisenhardt and Martin, he developed the information to motivate the success assisted in chaotic circumstances. Creation of information is created by learning and improving an institution and its knowledge. According to Scharmer, knowledge-building companies cultivate employee capacity and self-experience in order to develop new experiences, grow, and focus on each stage of the company.

\section{Knowledge Retention}

Kanto describes the conservation of information as practices related to the management of employee turnover and the resulting lack of experience that is a fundamental advantage of the company. Once employees leave a company for some cause, professional information can be lost. When children's boomers retire, it will become a considerably more pressing task to retain and keep the best employees.

\section{Job Satisfaction}

Spector says that job satisfaction is defined as how much people like their jobs (fulfilment) or hate them (unsatisfaction). Employment satisfaction will lead to job performance. The satisfaction of the profession, as defined in Shaikh, indicates that the workers enjoy their job or the positive and happy condition of the worker after assessment. The value of job satisfaction varies according to Fritzsche and Parrish because of the emotions that the individual has in his / her career. Locke also defined job satisfaction as "a component of the obvious relation between what one wants from one's work and what one sees as an advertisement" and the degree to which a worker feels firmly or contrary to his job. The word job satisfaction is similar to the concept of happiness of the worker. The general nature of workplace engagement and functioning is job happiness, as stated by Grant. Three satisfaction indicators are included in the definition: emotional, physical and social. Satisfaction is a primary indicator of human and organizational efficiency. Mismanagement, truancy, presentism, abolishing leave and selling are the result of low satisfaction. The job satisfaction endorsed by Vroom often coincides with the motivation exchange, in which the root of job gratification can be connected with social issues, confidence and self-actualization.

\section{Knowledge Management in Organization}

Like the word ' knowledge,' it is also challenging to describe the phrase ' Information Management' (KM). Ultimately, the scale and form of issues that KM is used to consider determine for each company at last the proper definition. In any case, what is most relevant is that each interpretation concentrates on the KM to improve methods of collaboration and appreciation. While KM has earned a terrible name in some quarters because of the fizzled cases of experts making a fast buck, KM is in reality digging in. Spiegler has shown that the KM is simply another thinking, segregated by and removed from data systems, preference of emotionally supportive networks and the management of the data in the past because of the unique nature of the "wisdom" aspect regarding the question of whether KM is "another thought." The importance of information in culture has been viewed. 
According to Becerra-Fernandez, the universal belief that learning to live separately, and primarily among employees, is the wealthiest commodity of the enterprise it represents the value of the processes that facilitate production, sharing and use. Given the increasing value of information and modes of instruction, Fahey and Prusak also recognized that organizations are not mainly well managed either. The desire to concentrate on learning and knowledge sources, and to better monitor them, has led to the development of the concept and routine for (KM). Bimpitsos and Petridou, have said that organizations work in an area defined as instability, failure and transition, can contribute to the emergence of various problems. It involves other factors, including increased globalization, accelerated technological changes, the production of professional workplace qualifications and improved performance. The power group, Savaneviciene and Stakeviciute, has announced itself to seek and adventure the properties at their move with a common aim to achieve a target. The criteria to high job satisfaction for instance, task design, ability diversity and complexity has been widely studied according to Glisson and Durick. Nonetheless, among the many job satisfaction indicators to be researched, the challenges of KM have not been listed. Generally speaking, it seems that KM literature in the previous study has scarcely dealt with.

Dominguez defined KM as fundamental elements to the fulfillment of a client. The distinctive difficulties faced by organizations must be understood by Othman, who makes critical use of the KM system. This allows it possible for all organizations to work with these properties. The use of a variety of activities to help organizations and monitor their success while they focus on their state of mind and their procedures as Ortega-Parra and Sastre-Castillo say. With the help of Yew, companies are looking to develop the workplace conference and to find the perfect way to maintain the morale of their workers. The organization's operations, as suggested by Tiwari and Saxena can be improved through the operation of the KM available to the organization in areas such as staff service, expertise and adaptability.

More precisely, few KM activities can impact the roles of workers, which can include registration and choosing, planning and development, assessment of results, collaboration and compensation and incentives. Nevertheless, as reported by Fong, staff chooses to leave the organization, the awareness would eventually be lost. That's why companies are trying to improve (KM) protecting, appropriating, recognizing and bureaucratic knowledge processes. The study is based on the interaction between KM and employee satisfaction, organizational accountability on the one side, and the company on the other. The essential parts analyze the logical context, explore method, research concept and hypotheses to achieve this.

\section{JUSTIFICATION FOR USING QUANTITATIVE DATA}

Quantitative and qualitative methods are two different techniques used for data collection. The quantitative method is based on distributing questionnaires over specified number of respondents, while the qualitative depends on conducting interview questions to study the point of view regarding a specific topic. Both methodologies will be implemented in the research.

Research Design

The research design (Figure 1) is made up of six elements, and they are listed as follows:

- Questions of the Research: The primary motivation behind the research is to address the impact of knowledge management on organizational commitment in the Organizations.

- Methods Used: Is a tool used for collecting data, both methods will be practiced in the research. Data Collected: Data will be gathered through distributing surveys.

- Variables: The dependent and independent variables are two different types and both will be studied in the research.

- Data Analysis: Data will be analyzed using the SPSS statistical tool for hypotheses validation

- Theoretical Framework: addressed through previous studies and researchers and it is mentioned in the review of the literature.

\section{Instrumentation}

The research will practice both methodologies for data collection. The quantitative methodology will be distributed among 100 respondents in different positions. The collected data will be analyzed using the SPSS statistical tool, and the outcomes will be viewed in the form of statistical Figure 1 and inferential statistics for hypotheses validation. 


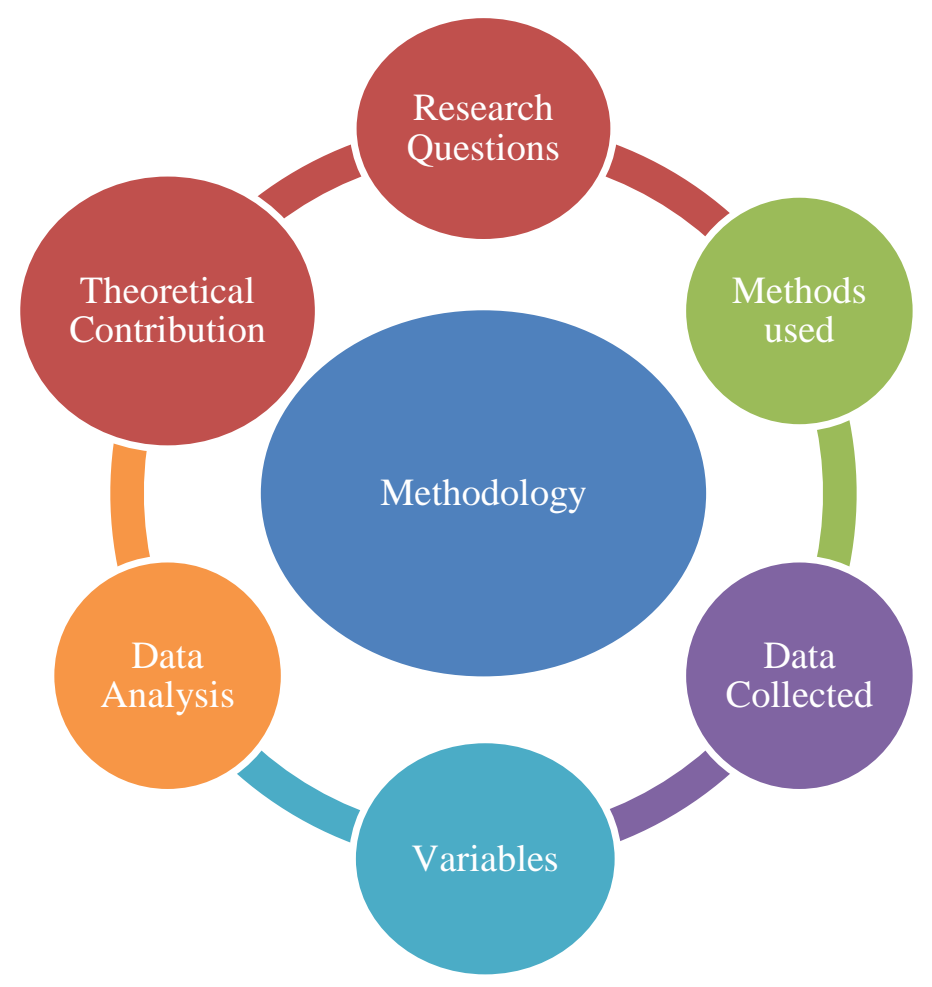

Fig 1. Research Design

\section{Regression}

Table 1: regression analysis of relationship between Knowledge management and employees commitment Model Summary

\begin{tabular}{|l|r|r|r|r|}
\hline Model & \multicolumn{1}{|c|}{$R$} & R Square & \multicolumn{1}{c|}{$\begin{array}{c}\text { Adjusted R } \\
\text { Square }\end{array}$} & $\begin{array}{c}\text { Std. Error of the } \\
\text { Estimate }\end{array}$ \\
\hline 1 & $.546^{2}$ & .299 & .287 & .882 \\
\hline
\end{tabular}

a. Predictors: (Constant), Knowledge management is enhanced through ELearning Systems

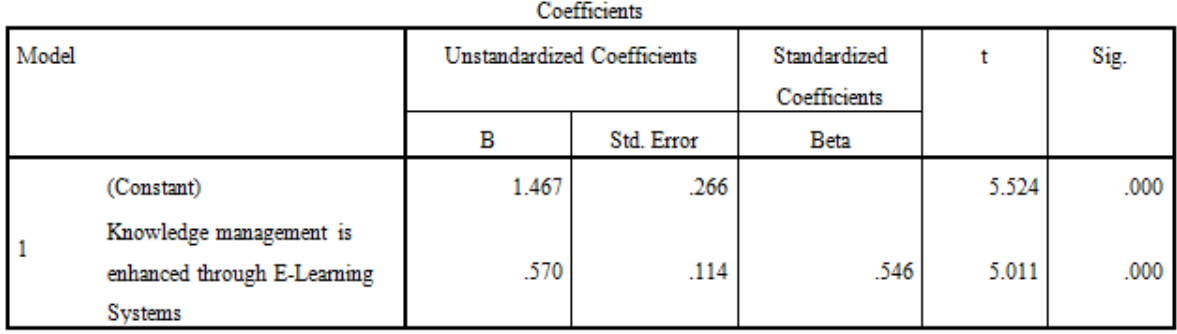

a. Dependent Variable: E-Leaming tools enhances team cooperation

The above regression analysis showed in Table 1, a standard error of 0.00 which is much lower than 0.05 which means the null hypothesis which states that "There is an insignificant relationship between Knowledge management and employees commitment", and the alternative hypothesis which states that "There is a significant relationship between Knowledge management and employees commitment." is accepted. As for the R-Square, it showed a sign of 29.9\%, which is above $25 \%$ this means that there is a strong relationship among the research variables. 
Table 2: regression analysis of relationship between E-Learning and employee's commitment

\begin{tabular}{|l|l|l|l|l|}
\hline Model & \multicolumn{1}{|c|}{ R } & R Square & \multicolumn{1}{c|}{$\begin{array}{c}\text { Adjusted R } \\
\text { Square }\end{array}$} & $\begin{array}{l}\text { Std. Error of the } \\
\text { Estimate }\end{array}$ \\
\hline 1 & $.610^{\mathrm{z}}$ & .373 & .362 & .834 \\
\hline
\end{tabular}

a. Predictors: (Constant), E-Learning helps employees achieve satisfaction in their workplace

\begin{tabular}{|c|c|c|c|c|c|c|}
\hline \multicolumn{7}{|c|}{ Coefficients } \\
\hline \multirow{2}{*}{\multicolumn{2}{|c|}{ Model }} & \multicolumn{2}{|c|}{ Unstandardized Coefficients } & \multirow{2}{*}{$\begin{array}{l}\text { Standardized } \\
\text { Coefficients } \\
\text { Beta }\end{array}$} & \multirow[t]{2}{*}{$\mathrm{t}$} & \multirow[t]{2}{*}{ Sig. } \\
\hline & & B & Std. Error & & & \\
\hline & (Constant) & 1.272 & .259 & & 4.904 & .000 \\
\hline 1 & $\begin{array}{l}\text { E-Learning helps employees } \\
\text { achieve satisfaction in their } \\
\text { workplace }\end{array}$ & .601 & .102 & .610 & 5.920 & .000 \\
\hline
\end{tabular}

a. Dependent Variable: E-Leaming tools enhances team cooperation

The above regression analysis showed in table 2, a standard error of 0.00 which is much lower than 0.05 which means the null hypothesis which states that "There is an insignificant relationship between E-Learning and employees' commitment", and the alternative hypothesis which states that "There is a significant relationship between E-Learning and employees commitment" is accepted. As for the R-Square, it showed a sign of $37.3 \%$, which is above $25 \%$ this means that there is a strong correlation among the research variables.

Table 3: regression analysis of correlation among knowledge enhancement and employee's commitment

\begin{tabular}{|l|r|r|r|r|}
\hline Model & \multicolumn{1}{|c|}{ Model Summary } \\
\hline 1 & $.488^{2}$ & .238 & \multicolumn{1}{c|}{$\begin{array}{c}\text { R Square } \\
\text { Square }\end{array}$} & $\begin{array}{c}\text { Std. error of the } \\
\text { Estimate }\end{array}$ \\
\hline
\end{tabular}

a. Predictors: (Constant), The knowledge I've gained through the Bank e-

learning system enables me to do my job better

Coefficients

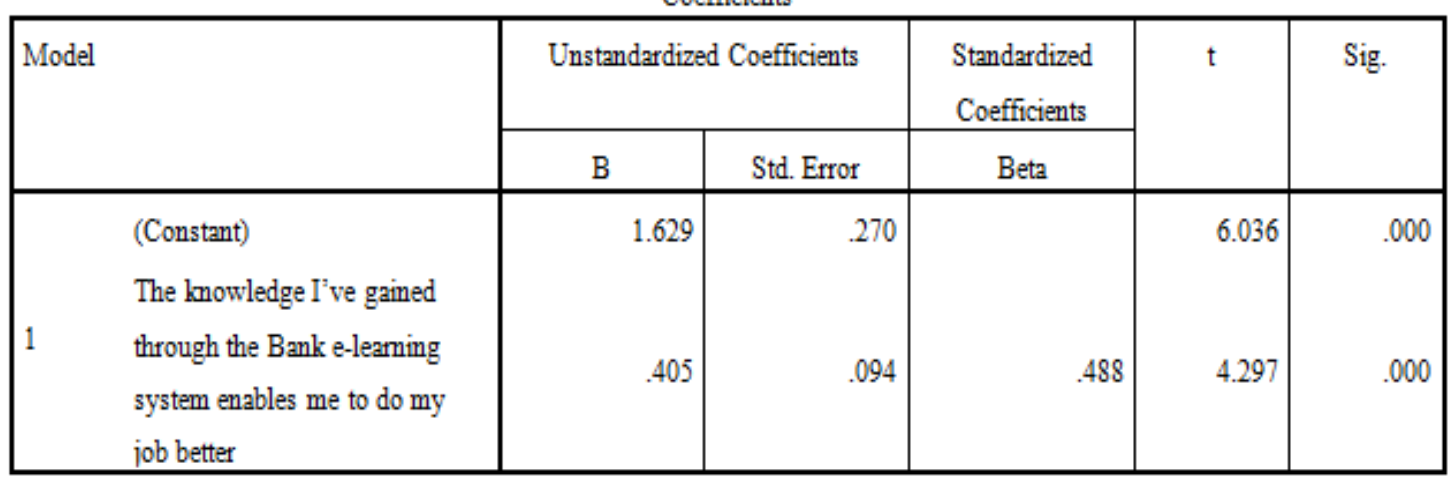

Dependent Variable: E-Leaming tools enhances team cooperation

The above regression analysis showed in table 3, a standard error of 0.00 which is much lower than 0.05 which means the hypothesis which reveals that "There is an insignificant correlation among knowledge enhancement and employees commitment" is not accepted, and the alternative hypothesis which states that "There is a significant correlation among knowledge enhancement and employees commitment" is accepted. As for the R-Square, it showed a sign of $23.8 \%$, which is near $25 \%$ this means that there is a strong correlation among the research variables. 


\section{Pearson Correlations}

Table 4: Implemented to test of Pearson correlations Correlations

\begin{tabular}{|c|c|c|c|c|c|c|}
\hline & & $\begin{array}{l}\text { E-Leaming tools } \\
\text { enhance team } \\
\text { cooperation }\end{array}$ & $\begin{array}{l}\text { Motivation is } \\
\text { enhanced through } \\
\text { E-leaming tools }\end{array}$ & $\begin{array}{c}\text { E-Leaming } \\
\text { systems enhance } \\
\text { work engagement }\end{array}$ & $\begin{array}{l}\text { E-Learning helps } \\
\text { employees achieve } \\
\text { satisfaction in their } \\
\text { workplace }\end{array}$ & $\begin{array}{c}\text { Employees use E- } \\
\text { Leaming tools to } \\
\text { develop their } \\
\text { skills }\end{array}$ \\
\hline \multirow{3}{*}{$\begin{array}{l}\text { E-Learning tools } \\
\text { enhances team } \\
\text { corporation }\end{array}$} & $\begin{array}{l}\text { Pearson } \\
\text { Correlation }\end{array}$ & 1 & $.361^{* *}$ & $.500^{* *}$ & $.610^{* *}$ & $.589^{4 *}$ \\
\hline & Sig. (2-tailed) & & .004 & .000 & .000 & .000 \\
\hline & $\mathrm{N}$ & 61 & 61 & 61 & 61 & 61 \\
\hline \multirow{3}{*}{$\begin{array}{l}\text { Motivation is } \\
\text { enhanced through E- } \\
\text { leaming tools }\end{array}$} & $\begin{array}{l}\text { Pearson } \\
\text { Correlation }\end{array}$ & $.361^{* *}$ & 1 & $.588^{* *}$ & $.590^{* *}$ & $.374^{* *}$ \\
\hline & Sig. (2-tailed) & .004 & & .000 & .000 & .003 \\
\hline & $\mathrm{N}$ & 61 & 61 & 61 & 61 & 61 \\
\hline \multirow{3}{*}{$\begin{array}{l}\text { E-Learning systems } \\
\text { enhances work } \\
\text { engagement }\end{array}$} & $\begin{array}{l}\text { Pearson } \\
\text { Correlation }\end{array}$ & $.500^{* *}$ & $.588^{* 4}$ & 1 & $.670^{4 *}$ & $.482^{* *}$ \\
\hline & Sig. (2-tailed) & .000 & .000 & & .000 & .000 \\
\hline & $\mathrm{N}$ & 61 & 61 & 61 & 61 & 61 \\
\hline \multirow{3}{*}{$\begin{array}{l}\text { E-Leaming helps } \\
\text { employees achieve } \\
\text { satisfaction in their } \\
\text { workplace }\end{array}$} & $\begin{array}{l}\text { Pearson } \\
\text { Correlation }\end{array}$ & $.610^{* *}$ & $.590^{4 *}$ & $.670^{4 *}$ & 1 & $.586^{4 *}$ \\
\hline & Sig. (2-tailed) & .000 & .000 & .000 & & .000 \\
\hline & $\mathrm{N}$ & 61 & 61 & 61 & 61 & 61 \\
\hline \multirow{3}{*}{$\begin{array}{l}\text { Employees use E- } \\
\text { Leaming tools to } \\
\text { develop their skills }\end{array}$} & $\begin{array}{l}\text { Pearson } \\
\text { Correlation }\end{array}$ & $.589^{* *}$ & $.374^{* *}$ & $.482^{* *}$ & $.586^{4 *}$ & 1 \\
\hline & Sig. (2-tailed) & .000 & .003 & .000 & .000 & \\
\hline & $\mathrm{N}$ & 61 & 61 & 61 & 61 & 61 \\
\hline
\end{tabular}

Pearson Test had been implemented to test whether there is a positive or negative relationship between the research variables as shown in table 4 , and the results are as follows:

- Positive correlation among team corporation and motivation (0.361)

- Positive correlation among team corporation and work engagement $(0.50)$

- Positive correlation among team corporation and job satisfaction (0.610)

- Positive correlation among team corporation and skills development (0.589)

- Positive correlation among motivation and work engagement (0.588)

- Positive correlation among motivation and job satisfaction (0.590)

- Positive correlation among motivation and skills development (0.374)

- Positive correlation among engagement and job satisfaction (0.670)

- Positive correlation among engagement and skills development (0.482)

- Positive correlation among satisfaction and skills development (0.586)

Validity and Reliability

Table 5: The reliability Statistics of data collected

Reliability Statistics

\begin{tabular}{|r|r|}
\hline Cronbach's Alpha & N of Items \\
\hline .894 & 13 \\
\hline
\end{tabular}


The validity of the data collected had been tested using the validity and reliability analysis as shown in table 5 . The Cronbach Alpha should indicate a sign between 0.7 and 1 to ensure that the collected data are valid and ready for statistical analysis. Referring to the Cronbach Alpha mentioned in the above table, it showed a sign of 0.894 which is between 0.7 and 1 , this means that the data collected is valid and ready for statistical analysis.

\section{Theoretical Framework and Hypothesis}

The paper describes the conceptual framework used by the evolving systems and by incorporating previous studies and literature. Wise information, knowledge sharing, development of knowledge and knowledge preservation are activities adapted as an independent variable (IV). Thus, employee satisfaction as a predictor is the dependent variable (DV). In this portion, alongside the variable overview and the association with another analysis, you will find the definition of each variable. This research would investigate and suggest hypotheses for the interaction between the independent variables and the dependent variable.

\section{Knowledge Acquisition and Job Satisfaction}

The acquisition of knowledge (creation) requires an opportunity to formulate, and integrate into the organization, original thoughts, knowledge and arrangements. The KM scale developed by Darroch has been used to assess KM activities in the organizations surveyed based on Jayasingam, researching them. The metric requires the development of information. According to Jayasingam this research concentrates on the success of KM projects viewed by individuals with the consequences of KM projects instead of taking objective measures as the KM outcome were difficult to measure. Bose notes that KM projects are constant, and continuing programs and success assessments of $\mathrm{KM}$ projects should be seen as factors that contribute to or strengthen an organization rather than as an end alone. The degree of change is therefore used instead of the level of achievement as success calculation. The analyst then suggests that the correlations are between the acquisition of knowledge and employee satisfaction.

Hypothesis 1: The relationship between knowledge acquisition and job satisfaction

\section{Knowledge Sharing and Job Satisfaction}

The exchange of information between individuals, communities, organizations and institutions is a function of knowledge sharing. The association between job satisfaction and the sharing of knowledge is highly correlated to the value of 0.934 based on Saeed results. Saeed proposed that information exchange would be more relevant than worker efficiency based on the results. Improved incentives for workers to share knowledge and other personnel to develop new concepts, to discuss facts, and to make an essential commitment to achieving the goals of the organization. This is also evident from the findings of this study, which the workers seek to share knowledge with others to enhance their job performance. In line with Trivellas, this finding also explored the positive connection between sharing knowledge and interaction with the workplace. The study concludes that the correlation between the exchange of information and employee satisfaction is fulfilled.

Hypothesis 2: There is a relationship between knowledge sharing and job satisfaction

\section{Knowledge Creation and Job Satisfaction}

Knowledge development applies in turn to the capability of the company, from publications and technologies to management practices, to developing a new and useful concept and approach in different areas of the corporate operations. According to the research by Prunzinsky, the development of information does not affect happiness at work. This could be attributed to the research background. It is likely that neither acquisition of information (particularly from sources or collaborators outside the organization) nor creation of new knowledge may be essential for the nature of the work carried out in that municipal institution. Such practices are not supported by the organization's sponsorship or recompense. We, therefore, have no effect on productivity at work. The researcher then concludes that the connection between generating information and pleasing the workforce. Based on the above study, the researcher therefore proposed for the following hypothesis

Hypothesis 3: There is a significant relationship between Knowledge Creation and Job Satisfaction

\section{The Relationship between Knowledge Retention and Job Satisfaction}

Information preservation relates to a critical strategic tool, the activities related to staff change reduction and associated professional information depletion. The critical KM method of this organization was information conservation, which implies that the consistency and maintenance of knowledge were crucial for the functioning of the company. This is to be anticipated as, when developing path-dependent approaches, an entity wants a comprehensive and meaningful view of its past. The Team, therefore, needs to understand the external forces and the organization's structural and regulatory climate. The remaining knowledge retention and job satisfaction are based on a study by Kianto. The findings specifically show that information exchange is the primary KM mechanism in the company and encourages job satisfaction for most classes of workers. The writer then suggests that the exploration of generating 
information and rewarding workers. Based on the above study, the researcher therefore proposed for the following hypothesis

Hypothesis 4: There is significant relationship between Knowledge Retention and Job Satisfaction

\section{CONCLUSIONS}

Finally, this design paper provides a broad understanding of knowledge management and happiness in work. In consideration of research papers and ideas published by academics and experts in this area, the literature from past studies is reviewed. This research also explores the end goal of clarifying and interpreting the effect of information management on the productivity of workers through numerous performance reports in the past. A systematic analysis examination is also carried out to research the elements to be included in the study addressing the aspects of information management and job satisfaction. The happiness of an employee can be shown with the calculation of a person's job satisfaction that KM practices. A philosophical structure is proposed as the basis for conducting the study, using the principle of embracing and adapting. More research should be done to improve the understanding of concepts and the impact of KM on the happiness of workers.

\section{References}

1. K. W. Juniarta, “Bussiness Process Management Initiative,” Jan. 2019.

2. Haochen $\mathrm{Li}$ and Zhiqiang Zhan, "Bussiness-driven automatic IT change management based on machine learning," 2012 IEEE Network Operations and Management Symposium, Apr. 2012.

3. M. Simanjuntak, N. E. Putri, L. N. Yuliati, and M. F. Sabri, "Enhancing customer retention using customer relationship management approach in car loan bussiness," Cogent Business \& Management, vol. 7, no. 1, p. 1738200, Jan. 2020.

4. L. Matosas-López, "How to improve the development of competencesin bussiness and management studies using ICT?," Brazilian Journal of Development, vol. 5, no. 6, pp. 5792-5804, 2019.

5. O. Oktavianty, "BUSSINESS PROCESS REENGINEERING APPROACH FOR QUALITY REPORTING PROCESS (Case Study at PT D. Perdana, Pasuruan)," Journal of Engineering and Management in Industrial System, vol. 6, no. 1, pp. 1-10, Oct. 2018.

6. P. C. Olsen, "Department of bussiness management," The Journal of the American Pharmaceutical Association (1912), vol. 20, no. 11, pp. 1181-1184, Nov. 1931.

7. I. D. Rutherfurd, “Australia's Environment and Its Management," Environmental Science, Jul. 2018.

8. C. J. Barrow, "Structure, function and management of the environment," Developing the Environment, pp. 22-34, Sep. 2014.

9. L. S. Pheng, "Introduction to Project Management," Project Management for the Built Environment, pp. 114, Oct. 2017.

10. L. S. Pheng, "Project Management Processes," Project Management for the Built Environment, pp. 27-46, Oct. 2017.

11. L. S. Pheng, "Project Integration Management," Project Management for the Built Environment, pp. 47-61, Oct. 2017.

12. M. Tolba, "Environmental management," Environment International, vol. 1, no. 3, pp. 121-127, 1978.

13. C. Park, "Handbook of Environmental Management and Technology: Handbook of Environmental Management and Technology," Environment International, vol. 26, no. 1-2, p. 117, Aug. 2000.

14. K. Booles, "Management of diabetes within a secure environment," Practical Diabetes, vol. 31, no. 2, pp. $62-$ 66, Mar. 2014.

15. R. C. Papademetriou, "MagLabAn Intelligent Management Learning Environment," Proceedings of the Fifth International Symposium on Business Modeling and Software Design, 2015.

16. R. Levett, "From eco-management and audit (EMAS) to sustainability management and audit (SMAS)," Local Environment, vol. 1, no. 3, pp. 329-334, Oct. 1996.

17. B. Ronen, J. S. Pliskin, and S. Pass, "Constraint Management in a Bottleneck Environment (DRAFT)," Oxford Medicine Online, Apr. 2018.

18. M. E. Pfahl, "Teaching Sport Management and the Natural Environment," Sport Management and The Natural Environment, pp. 29-37, May 2015.

19. L. D. Neirotti, "Management and Leadership Related to Sport and the Environment," Sport Management and The Natural Environment, pp. 53-59, May 2015.

20. W. Beinart and L. Hughes, "Resistance to Colonial Conservation and Resource Management," Environment and Empire, Oct. 2007.

21. J. A. Layzer, "Ecosystem-Based Management and the Environment," Natural Experiments, pp. 267-292, Aug. 2008. 
22. D. Cooley, "Disease-management components of advanced integrated pest management in apple orchards," Agriculture, Ecosystems \& Environment, vol. 66, no. 1, pp. 31-40, Nov. 1997.

23. I. Blenkharn, "NEW HORIZONS IN HOSPITAL ENVIRONMENT AND HYGIENE MANAGEMENT," International Journal of Hospital Environment and Hygiene Management, vol. 1, Aug. 2012.

24. N. Sonuç, "Environment, Tourism and Sustainability (Ecotourism Management, Environment and Sustainable Tourism)," Encyclopedia of Sustainable Management, pp. 1-6, 2020.

25. N. Sonuç, "Environment, Tourism and Sustainability (Ecotourism Management, Environment and Sustainable Tourism)," Encyclopedia of Sustainable Management, pp. 1-6, 2020.

26. M. Thummarukudy, "Chapter 11 Waste: Disaster Waste Management: An Overview," Environment Disaster Linkages, pp. 195-218, Jan. 2012. 